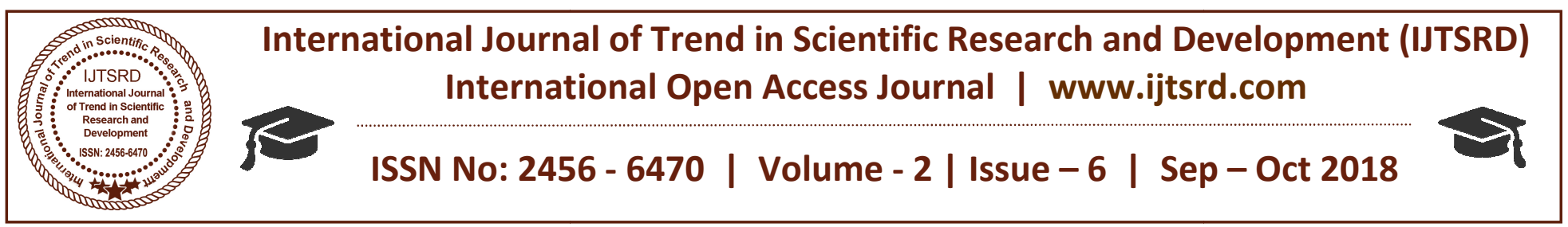

\title{
Future Antenna for 5G Mobile Communications
}

\author{
Nazia Hameed ${ }^{1}$, Dr. Vipin Gupta ${ }^{2}$ \\ ${ }^{1}$ M.Tech Scholar, ${ }^{2}$ Principal \\ ${ }^{1}$ Department of Electronics \& Communication Engineering \\ SSCET Badhani, Pathankot, Punjab, India
}

\begin{abstract}
The smart phone users are growing day by day because of the dynamic and user friendly interactive applications. The internet is the base for smart phone users and presently we have 4G technology and expecting $5 \mathrm{G}$ in coming years. As for analysis the $5 \mathrm{G}$ mobile technology greatly increases communication capacity in large amount of spectrum in the millimeter wave bands. The paper describes the basic fundamentals of the antenna used for the coming $5 \mathrm{G}$ technology. This paper describes millimeter wave antenna design for future $5 \mathrm{G}$ wireless system. The paper review objectives of millimeter wave antenna for $5 \mathrm{G}$.
\end{abstract}

Keywords: 5G, Millimeter wave antenna, Micro strip.

\section{INTRODUCTION}

The early communication systems supported only analogy voice and now provide wide range of different applications to large number of users. First generation of mobile system supported voice only. Within last few years we have seen gradual development of mobile communications by birth of $2 \mathrm{G}, 3 \mathrm{G}$ and $4 \mathrm{G}$ wireless networks respectively. Digital networking communication techniques like Modulations, Cellular frequency reuse, Packet switching and physical layer simulation etc. have resulted in this change. With the increasing demand of smart devices, now a day's IP based networks has become a necessity. Resultant, new multimedia applications for mobile users .Market is flooded with these applications and has open up new ventures for mobile user and service providers. The future of mobile communications is likely to be very different to that which we are used to today. While demand for mobile broadband will continue to increase, largely driven by ultra-high definition video and better screens, we are already seeing the growing impact of the human possibilities of technology as the things around us become ever more connected. The upcoming 5th generation cellular network ("5G") is anticipated to exhibit a uniform Gbps data throughput experience across a vast range of user scenarios. $5 \mathrm{G}$ is more than just a new wireless radio technology. It is a door opener to new communications possibilities and use cases, many of which are still unknown. Enabled by $5 \mathrm{G}$, a programmable world will transform our lives, economy and society. Data throughput will be enhanced by more than a hundred fold. Mobile and wireless communication networks (GSM, 2G, 2.5G, and $3 \mathrm{G}$ ) have made tremendous growth in the last fifteen years. The multimedia application for cellular system are limited to carrier frequency spectrum between $700 \mathrm{MHz} \& 2.6 \mathrm{Ghz}$.The global spectrum bandwidth allocation for all the cellular networks does not exceed $780 \mathrm{MHz}$ where each Service provider has approximately $200 \mathrm{MHz}$ across all of the different cellular bands of the available spectrum. For the bandwidth aspects, here millimetre wave mobile communications technique is introduced and a microstrip antenna has developed for 5G cellular network/device. The millimeter wave antenna must be compact in size to fit into hand held devices.

\section{G TECHNOLOGY}

Till now 5G standards are not available. So researches have started to put the base for the technology that will provide these standards. This technology mostly consists of wireless access systems, frequency utilization, power consumption, antenna and propagation.

\section{A. 5G SPECTRUM}

There is an enormous expanse in millimeter wave spectrum specifically $28 \mathrm{GHZ}$ and beyond that is overlooked till now.FCC proposed new rules for 
wireless broadband frequencies of $28 \mathrm{GHz}, 37 \mathrm{GHz}$, $39 \mathrm{GHz}$ and $64-7 \mathrm{GHz}$ bands. Researches are targeting these frequencies for $5 \mathrm{G}$.

\section{B. 5G OBJECTIVES}

The goal of $5 \mathrm{G}$ will be on better coverage and low cost. The important target will be on capacity with high speed and high information rates.

\section{CELLULAR SYSTEMS-THE PRESENT}

Further improvements and advances in technology led to the PCS (Personal Communication Services) in 1995. One example of a PCS system is the DCS-1900 which uses the $1850-1990 \mathrm{MHz}$ band and is in use today. This system is based on TDMA and has 200$\mathrm{kHz}$ channel spacing and eight time slots. The system also provides services like paging, caller ID, and email. In a PCS system, the cells are further divided into macro cells, microcells and picocells to facilitate better coverage as shown in the following Figure.

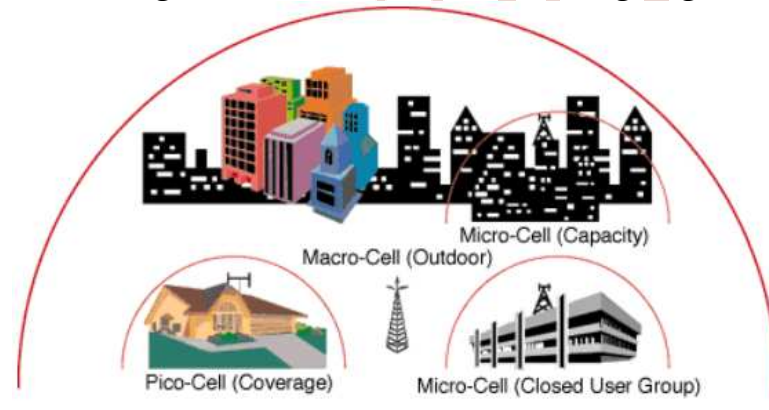

Indoor / Outdoor Coverage

PCS Cell structure

\section{VISION FOR THE FUTURE}

According to the Cellular Telecommunications Industry Association (CTIA), today there exist more than 60 million wireless customers. This figure is hard to imagine considering the fact that cellular service was invented about 50 years ago. Over the last 25 years, the wireless market has grown steadily from a $\$ 3$ billion market to a $\$ 30$ billion market in terms of annual revenues.

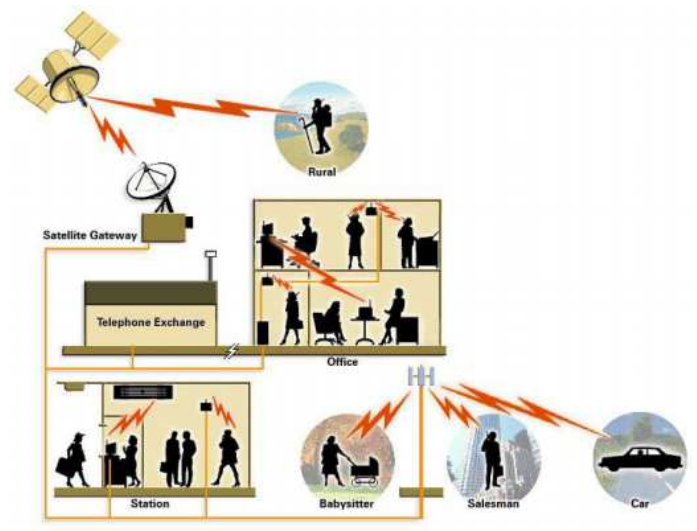

The future vision
The figure above shows the vision of the future. An integrated terrestrial/satellite multimedia system is envisioned. Global personal communication is to be supported via satellites using the satellite gateways to connect to the fixed ground network. Underground cable, optical fibers or fixed radio links would be used to link the gateways to the fixed networks. The fixed networks would be connected to cellular base stations providing radio links to mobile handsets or hand set units on vehicles. Indoor base stations located in offices and public places such as bus and rail stations, airports and shops would also be connected to the fixed network. In areas which cannot be provided coverage by terrestrial base stations or fixed networks, satellites would be used to connect to the personal handsets. Hence, in the future, the handsets would be such that they would support multimedia which is an integration of voice, data and video signals. Thus, the user would have access to a very wide range of services such as telephone, fax, electronic mail, World Wide Web, video conferencing, remote shopping and emergency services. In the present world cordless, indoor and other types of cellular phones are available for different applications

\section{HOW AN ANTENNA RADIATES}

In order to know how an antenna radiates, let us first consider how radiation occurs. A conducting wire radiates mainly because of time-varying current or an acceleration (or deceleration) of charge. If there is no motion of charges in a wire, no radiation takes place, since no flow of current occurs. Radiation will not occur even if charges are moving with uniform velocity along a straight wire. However, charges moving with uniform velocity along a curved or bent wire will produce radiation. If the charge is oscillating with time, then radiation occurs even along a straight wire as explained by Balanis.

The radiation from an antenna can be explained with the help of Figure 3.1 which shows a voltage source connected to a two conductor transmission line. When a sinusoidal voltage is applied across the transmission line, an electric field is created which is sinusoidal in nature and these results in the creation of electric lines of force which are tangential to the electric field. The magnitude of the electric field is indicated by the bunching of the electric lines of force. The free electrons on the conductors are forcibly displaced by the electric lines of force and the movement of these charges causes the flow of current which in turn leads to the creation of a magnetic field. 
E
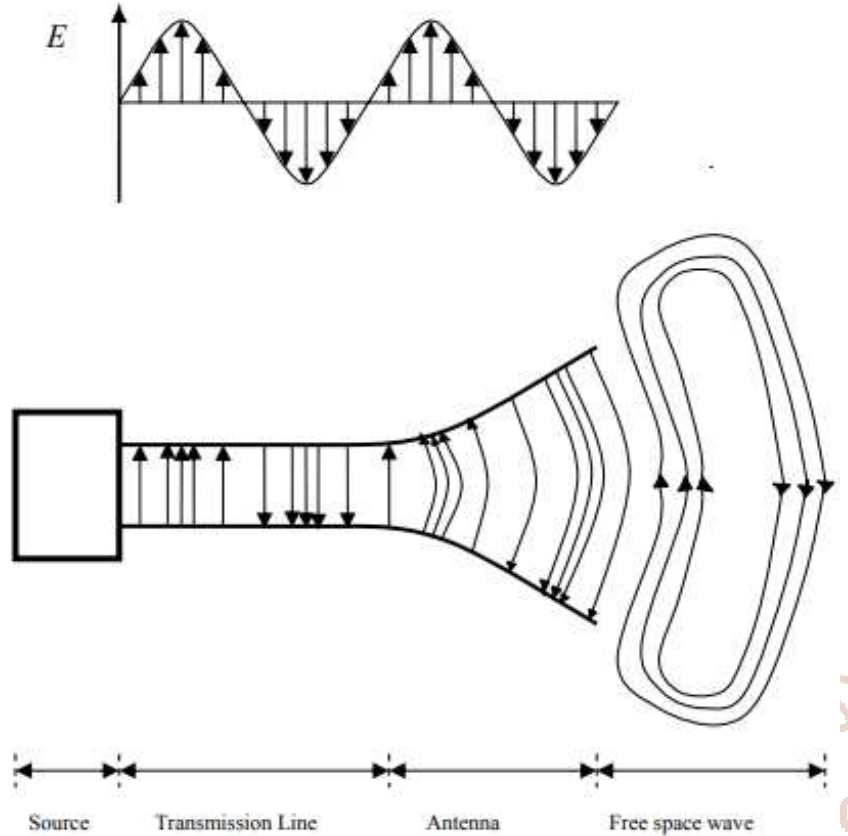

Radiation from an antenna

2. Theodore S. Rappaport, Shu Sun, RimmaMayzus, Hang Zhao, YanivAzar, "Millimetre Wave Mobile Communications for 5G Cellular", IEEE Access. Vol. 1, 2013.

3. T. S. Rappaport, F. Gutierrez, E. Ben-Dor, J. N. Murdock, Y. Qiao, and J. I. Tamir, "Broadband millimetre wave propagation measurements and models using adaptive beam antennas for outdoor urban cellular communications" ,IEEE Trans. Antennas Propag., vol. 61, no. 4, Apr. 2013.

4. M. Samimi, K. Wang, Y. Azar, G. N. Wong, R. Mayzus, H. Zhao, J. K. Schulz, S. Sun, F. Gutierrez, and T.S. Rappaport, " $28 \mathrm{GHz}$ angle of arrival and angle of departure analysis for outdoor cellular communications using steerable-beam antennas in New York City", in Proc. IEEE Veh. Technol. Conf., Jun. 2013.

5. M. Cudak, A. Ghosh, T. Kovarik, R. Ratasuk, T. Thomas, F. Vook, and P. Moorut, 'Moving towards mmwave-based beyond-4G (B-4G) Technology", in Proc. IEEE Veh. Technol. Soc. Conf., 2013.

6. H. Zhao, R. Mayzus, S. Sun, M. Samimi, J. K. Schulz, Y. Azar, K. Wang, G. N. Wong, F. Gutierrez, Jr., and S. T. Rappaport, “28 GHz millimetre wave cellular communication measurements for re_ection and penetration loss in and around buildings in New York City", in Proc. IEEE Int. Conf. Commun., Jun. 2013.

7. J. N. Murdock, E. Ben-Dor, Y. Qiao, J. I. Tamir, and T. S. Rappaport „,A $38 \mathrm{GHz}$ cellular outage study for an urban campus environment teee $^{\text {ece }}$ Proc. IEEE Wireless Commun. Netw. Conf., Apr. 2012.

8. S. Rajagopal, S. Abu-Surra, Z. Pi, and F. Khan, "Antenna array design formulti-Gbpsmmwave mobile broadband communication", in Proc. IEEE Global Telecommun. Conf., Dec. 2011.

9. G. Nair, "Single-feed Dual-frequency DualpolarizedSlotted Square Microstrip Antenna", Microw. Opt. Technol. Lett., 25, pp. 395-397, June 20, 2000.

\section{References:}

1. BrajlataChauhan, Sandip Vijay, S.C. Gupta, "Millimetre-Wave Mobile Communications Micro strip Antenna for 5G - A Future Antenna", International Journal of Computer Applications Volume 99- No.19, August 2014.

10. W.F. Richards, Y.T. Lo, and D.D. Harrison, "An ImprovedTheory Formicrostrip Antennas and Applications", IEEETrans. Antennas Propagat.29, pp. 38-46, Jan. 1981.

11. W.F. William F. Richards, "Micro strip Antennas", in Antenna Handbook, Y. T. Lo and 
S.W. Lee, Eds. New York: Van No strand Reinhold, 1993.

12. L. Alatan, M.I. Aksun, K. Leblebicioglu, and M.T. Birand, "Useof Computationally Efficient Method of Moments in the Optimization of Printed Antennas", IEEE Trans. Antennas Propagate., 47, pp. 725-732, Apr. 1999.

13. D.H. Shaubert, F.G. Garrar, A. Sindoris, and S.T. Hayes, "Microstripantennas with Frequency Agility and Polarization Diversity", IEEE Trans. Antennas Propagate. 29, pp. 118-123, Jan. 1981.

14. W.F. Richards and Y. T. Lo, "Theoretical and Experimental Investigation of a Micro strip Radiator with Multiple Lumped Linear Loads", Electromagn, 3(3-4), pp. 371-385, July-Dec. 1983.
15. S.C. Pan and K.L. Wand, "Dual Frequency Triangular Micro strip Antenna with Shorting Pin”, IEEE Trans. Antennas Propagate, 45, pp. 1889-1891, Dec. 1997.

16. B.F. Wang and Y.T. Lo, "Micro strip Antennas for Dual frequency Operation", IEEE Trans. Antennas Propagate.32, pp. 938-943, Sept. 1984, 137-145, Mar. 1979.

17. Deal W., N. Kaneda, J. Sor, Y. Qian, and T. Itoh, "A New Quasiyagi Antenna for Planar Active Antenna Arrays", IEEE.

18. Transactions on Microwave Theory and Techniques, 48(6), 910-918, Jun. 2000.

19. Wang H., D. Fang, L. Wang, and Y. Guo, "A Modi ${ }^{-}$edtshaped Probe-fed Circularly Polarized Micro strip Patch Antenna", Microwave Conference, 2008.Asia-Pacific, 1-4, Dec. 2008. 